\title{
Recovery processes of the brown alga Fucus gardneri following the 'Exxon Valdez' oil spill: settlement and recruitment
}

\author{
Peter G. van Tamelen ${ }^{1}$, Michael S. Stekoll ${ }^{1, *}$, Lawrence Deysher ${ }^{2}$ \\ ${ }^{1}$ Juneau Center, School of Fisheries and Ocean Sciences, University of Alaska, Fairbanks, 11120 Glacier Highway, Juneau, \\ Alaska 99801, USA \\ ${ }^{2}$ Coastal Resources Associates, Inc., 1185 Park Center Drive, Suite A, Vista, California 92083, USA
}

\begin{abstract}
The 1989 'Exxon Valdez' oil spill and subsequent cleanup efforts left many shorelines in Prince William Sound (Alaska, USA), especially in the higher tidal zones, mostly devoid of the dominant intertidal alga Fucus gardneri. Settlement and recruitment processes of F. gardneri were studied to determine the factors that can limit F. gardneri recolonization. Zygote settlement rates were initially lower at oiled sites relative to unoiled sites, but increased to values similar to those for unoiled sites in the lower intertidal zones after 3 yr. In the upper intertidal, settlement rates after 3 yr had not yet converged with those at unoiled sites. The low settlement rates of $F$. gardneri at oiled sites were probably due to low densities of reproductive plants and limited egg dispersal. Settlement was also negatively correlated to net flow of water The effect of substrate rugosity on settlement was investigated by using grooved ceramic tiles. We found that grooves enhance survival and recruitment of germlings in the high intertidal zone. Germlings survived best initially in deep, narrow grooves. After 2 yr there were more recruits in medium width, deep grooves. Manipulation of F. gardneri canopy over tiles revealed that $F$. gardneri canopy ameliorated heat and desiccation stress, but a whiplash effect dislodged small plants. Overall the positive effects of canopy were stronger than the negative effects. There were no significant herbivore effects on germling survival, but both recruitment and average thallus size were increased in the absence of herbivores.
\end{abstract}

KEY WORDS: Fucus - Oil spill - Algae - Pollution · 'Exxon Valdez' - Recruitment Dispersal - Settlement - Desiccation

\section{INTRODUCTION}

In March 1989, the 'Exxon Valdez' grounded on Bligh Reef in Prince William Sound, Alaska, USA, releasing almost 40 million liters of north slope crude oil. To remove oil from almost $1000 \mathrm{~km}$ of impacted shoreline a massive cleanup effort ensued, including washing by hand, bioremediation, and washing with hot, pressurized water (Nauman 1991, Mearns 1996). The spill and cleanup removed large areas of the dominant intertidal alga Fucus gardneri (Silva) (Fucus hereafter) from the intertidal (De Vogelaere \& Foster

\footnotetext{
- Addressee for correspondence.

E-mail:jfmss@acad1.alaska.edu
}

1994, Highsmith et al. 1996, Houghton et al. 1996, Lees et al. 1996, van Tamelen \& Stekoll 1996).

The recovery of fucoids after the 'Exxon Valdez' oil spill (Highsmith et al. 1996, Houghton et al. 1996, van Tamelen \& Stekoll 1996) and other oil spills (Southward \& Southward 1978, Rolan \& Gallagher 1991) has been clearly documented. Yet no studies have identified the ecological mechanisms that control recovery rates after oil spills (Paine et al. 1996). It has been suggested that recovery from the 'Exxon Valdez' oil spill was limited in the high intertidal by low recruitment due to high desiccation stress (De Vogelaere \& Foster 1994).

Recovery after a disturbance is often measured as a return to normal distributions of adult organisms, but 
these distributions can be a function of settlement and post-settlement survival patterns (Denley \& Underwood 1979, Roughgarden et al. 1988, Menge 1991). There is limited information on the settlement processes of marine macrophytes since it is difficult to identify and observe propagules within $24 \mathrm{~h}$ of settling (see Santelices 1990 and Chapman 1995 for reviews). In the only field study of settlement (sensu Connell 1985), Kendrick \& Walker (1991) found that dispersal distances were short for Sargassum spinuligerum in Western Australia. It has also been shown that fucoid settlement is inhibited at high water velocities (Norton \& Fetter 1981, Serrao et aI. 1996).
There are many factors that can affect post-settlement survival of Fucus spp. Grazers are generally found to negatively affect recruit survival (Lubchenco 1983. Hartnoll \& Hawkins 1985, Barker \& Chapman 1990, Chapman \& Johnson 1990, Benedetti-Cecchi \& Cinelli 1992), but Chapman (1989) found that grazers had little effect on Fucus spiralis recruits. The effect of adult canopies on germling survival also varies between studies (Menge 1976, Brawley \& Johnson 1991. 1993, Benedetti-Cecchi \& Cinelli 1992, Vadas et al. 1992). Crevices in rock surfaces have been suggested to enhance recruit survival (Lubchenco 1983) or settlement (Norton \& Fetter 1981) by providing a refuge

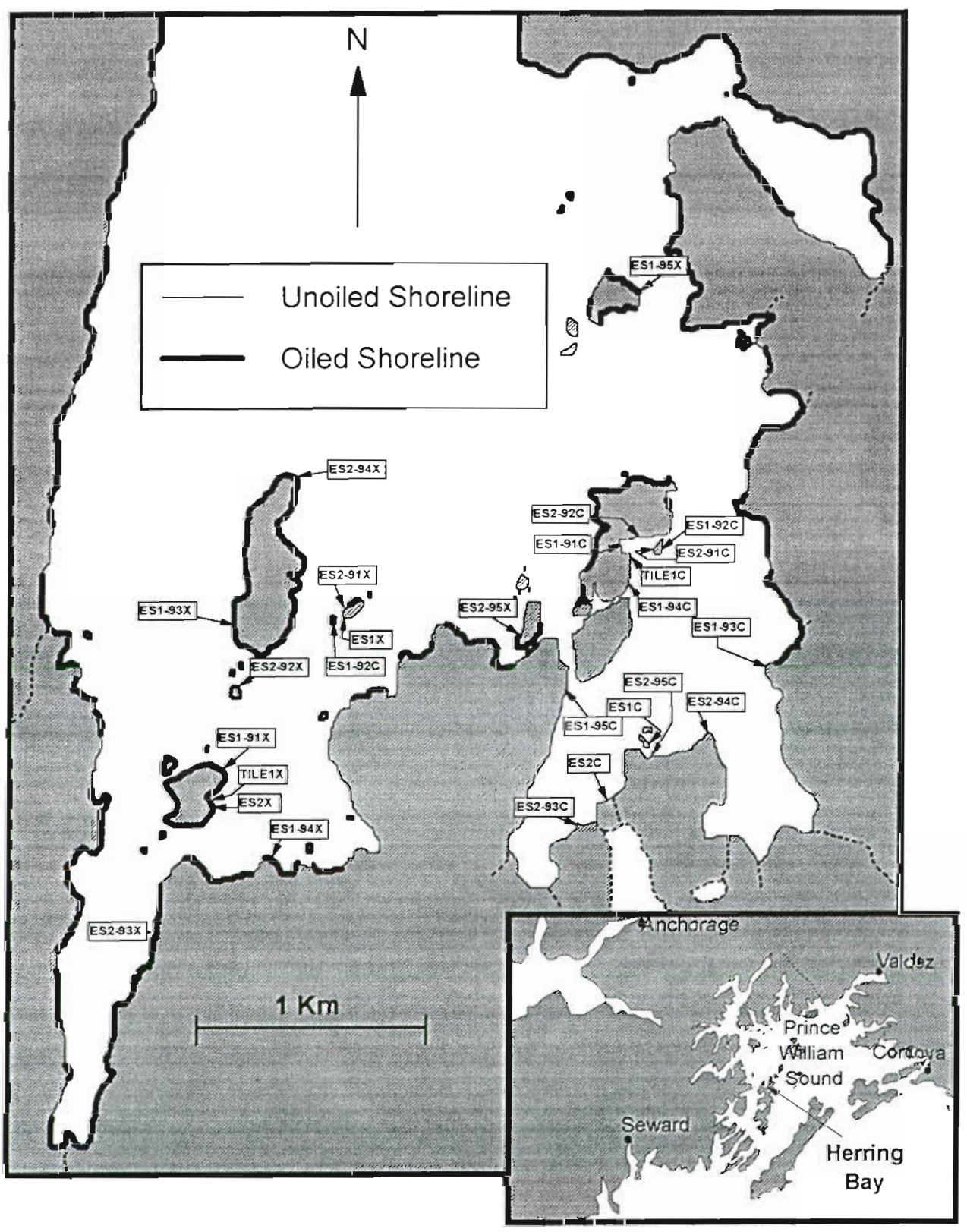

Fig. 1. Study sites in Herring Bay, Alaska, USA. X: oiled sites; C: unoiled sites; ES: sites used for egg settlement studies; TILE: sites used for ceramic tile experiments. The year the site was used is given after the dash. The number after ES indicates which sites (oiled/unoiled) were paired together. Two pairs of egg settlement sites were used in all 5 years: ES1X/ES1C and ES2X/ES2C. Two parrs of egg settlement sites were also used for the tile experiments: ES2-92X/ ES2-92C and ES2-93X/ES293C. Three pairs of egg settlement sites were used in the desiccation experiment: ES2X/ES2C, ES2-91X/ES291C and ES2-93K/ES2-93C. The oiled sites which are shown to be on unoiled shoreline were in areas which were actually unobserved by monitors and originally classified as unoiled shorelines The oiling data was obtalned from the Alaska Department of Natural Resources 
from herbivory (Hawkins 1981, Lubchenco 1983, Farrell 1991), but surface heterogeneities may also protect germlings from whiplash of adult plants, heat and desiccation stress (Jernakoff 1983, 1985) or dislodgement by waves (Norton 1983).

In order to understand the mechanism of recovery after the 'Exxon Valdez' oil spill, we investigated several of the above factors that may affect settlement and post-settlement survival or recruitment in a fucoid population. We assessed the settlement rates of Fucus in the field at both oiled and unoiled shorelines. We also measured the net water flow to determine the effect of currents and waves on settlement patterns. Since the role of grazers on Fucus spp. recruitment in the northeast Pacific Ocean is unknown, we tested the effects of grazers. In this study we experimentally separated the conflicting effects of canopy whiplash and canopy protection from desiccation stress. Finally, we tested the role of substrate heterogeneity on Fucus recruitment. The experiments presented here allow determination of those impacted shores that may be slow to recover based upon the physical and biological characteristics of the shore

\section{METHODS}

Study sites. Experiments were carried out in Herring Bay on the northern end of Knight Island in Prince William Sound, Alaska. Unoiled sites were chosen and matched with oiled sites using a variety of physical characteristics, such as slope, solar aspect, and wave exposure (van Tamelen \& Stekoll 1996). All unoiled sites were located in the south-eastern arm of the bay which was mostly unoiled or lightly oiled (Fig. 1). The oiled sites were located in the south-western arm of the bay. We considered the entire south-western arm of the bay as impacted because this area was recorded as receiving cleanup treatment.

Fucus egg settlement. Fucus settlement rates were measured at oiled and unoiled sites from 1991 through 1995 by deploying acrylic plates designed to catch Fucus eggs (Fig. 2). In this paper, 'Fucus eggs' refers to both fertilized (zygotes) and unfertilized eggs landing on the substrate. 'Plates' refers to these egg settlement plates as opposed to other settling and recruitment substrates described later. The plates were set out for 1 day at a time for 3 (1992-1995) or 4 (1991) days in a row, and the number of eggs on each plate was recorded daily. Plates were placed at each of 3 tidal levels along 4 equally spaced transects perpendicular to the shore. The tidal levels were the very high zone (2.95 $\mathrm{m}$ above mean lower low water, MLLW), high zone (2.45 $\mathrm{m}$ above MLLW), and mid zone $(1.45 \mathrm{~m}$ above MLLW). This procedure was performed at 4 pairs of oiled and unoiled sites for each year. Since only 4 pairs of sites could be sampled during a sampling period, a method of rotating site pairs was devised to assess both yearly variation and to sample a large number of sites. Two pairs of sites were used in all 5 years, but each year 2 new site pairs were added and 2 old site pairs were dropped. The distance to the nearest fertile Fucus plant from each plate was recorded beginning in August 1991.

The effects of net water flow on egg settlement were investigated in August and September 1994. Net flows were estimated by measuring the dissolution rate of plaster of Paris cylinders at each egg density site. The plaster was molded in plastic $35 \mathrm{~mm}$ film canisters with 3 inch (ca $7.6 \mathrm{~cm}$ ) stainless steel screws placed through the center of each mold before hardening. The cylinders were oven-dried at $40^{\circ} \mathrm{C}$ to constant weight. The cylinders were attached to the rock surface $2.45 \mathrm{~m}$ above MLLW at the midpoint of each site. The bottoms of the cylinders were at least $4 \mathrm{~cm}$ above the substrate and any nearby Fucus plants were removed in order to minimize abrasion. All cylinders retained their cylindrical shape throughout the experiment.

For the egg settlement studies, comparisons were made for each tidal level at each pair of sites. If either the raw or log-transformed variances were equal (Levene's test, $p=0.10$ ), then a 1-way ANOVA was performed on all sites, and contrasts between oiled and unoiled sites within a pair were used to detect differences. Otherwise, a Student's t-test was used to compare each pair of sites. If raw data variances or logtransformed data for each site pair were not homogeneous ( $F$-max test), then Satterthwaite's correction was used. Because the unit of replication for the overall sampling design is the site, overall statistics

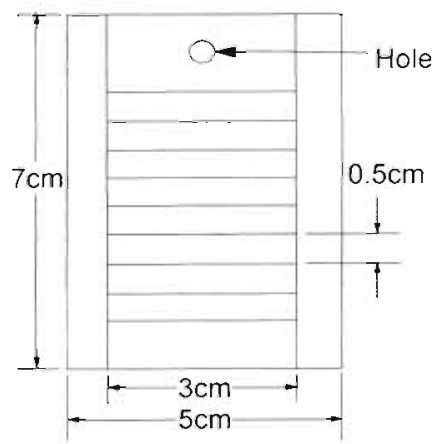

Cross Section Through Groove

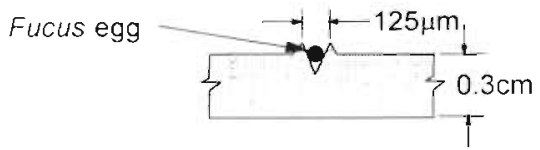

Fig. 2. Schematic diagram of a Fucus gardneriegg settlement plate used in this study 
were performed using Fisher's procedure for combining probabilities of similar tests (Sokal \& Rohlf 1981).

Fucus recruitment: desiccation. The effect of desiccation on Fucus germling survival was investigated by monitoring survival of germlings settled onto petri dishes and placed into areas of varying desiccation rates. On 3 May 1991 petri dishes $(9 \times 60 \mathrm{~mm})$ were seeded with about 140 eggs $\mathrm{cm}^{-2}$ in the lab at Juneau. 'Dishes' refers to these seeded petri dishes and differentiates them from the settlement plates. Seeding consisted of inducing fertile receptacles to release eggs in a vial with seawater and pouring this solution over the dishes, which were covered with sterile seawater in plastic containers. After seeding, the dishes were incubated for $27 \mathrm{~d}$ at 8 to $10^{\circ} \mathrm{C}$ with an $8 \mathrm{~h}$ light: $16 \mathrm{~h}$ dark cycle under 50 to $100 \mu \mathrm{mol} \mathrm{m} \mathrm{m}^{-2} \mathrm{~s}^{-1}$ of light intensity. The seeded dishes were kept on ice during shipment to Herring Bay. On 1 June 1991, 4 seeded dishes were bolted to random locations on rock surfaces at $2.45 \mathrm{~m}$ above MLLW at each of 6 sites (Fig. 1). At this time all germlings were about $0.5 \mathrm{~mm}$ in length. The percent cover of Fucus germlings was visually estimated on each dish initially and after $11 \mathrm{~d}$ in the field. For consistency all estimates of percent cover were made by a single observer (Dethier et al. 1993).

To account for some of the variation in germling mortality, we measured desiccation rates on 20 June 1991 by placing wetted cotton balls on freezer container lids in the field and measuring the loss of water from the cotton balls over time. One lid with one cotton ball was placed near each dish as the tide receded. The weight of the wetted cotton ball was about $5 \mathrm{~g}$. The lids and cotton balls were collected just before they would have been covered by the rising tide.

Observations of the petri dishes after the desiccation trials described above indicated that germlings survived only along the edges of dishes covered by Fucus canopy, suggesting that whiplash from adult plants removed germlings. To test effects of canopy only, seeded dishes were mounted on a plywood board and suspended just under the water surface in an area subjected to slight wave action. The bottom of the board was weighted to keep the board vertical. Herbivores were excluded from the board since it was suspended in open water. Desiccation was also eliminated as a source of mortality since the dishes were continuously submerged. Adult Fucus plants were suspended above 4 of the dishes, and 3 other dishes served as controls with no adult Fucus plants. Observations showed that the action of these experimental plants was similar to the action of plants attached to the shore. After $10 \mathrm{~d}$ in the field, germling density was measured under a dissecting microscope.

Fucus recruitment: canopy, substrate heterogeneity, and herbivory. The effects of substrate heterogeneity. tidal height, Fucus canopy, oiling level, and herbivores on Fucus germling survival and recruitment were assessed with a series of multi-factor experiments using tiles seeded with germlings. During the first $2 \mathrm{wk}$ of June 1992, tiles were seeded in the same manner as the dishes in the desiccation experiment. All of the following experiments were initiated on 4 July 1992. The tiles were made with Pine Lake Red Stoneware clay and fired at cone 10 with no glazes or colorants (Fig. 3). The 6 groove sizes were randomly ordered horizontally on each tile. 'Tiles' is used to differentiate these grooved tiles from the egg settlement plates and seeded petri dishes.

The size distribution of cracks in the natural substrate was recorded in a $20 \times 50 \mathrm{~cm}$ plot haphazardly placed in the supratidal zone devoid of plants. The width and length of all cracks in the plot were measured.

To evaluate the effects of adult Fucus canopy, tidal level, and oiling history on survival and recruitment, 8 tiles were deployed at each of 3 unoiled and matching oiled sites. At both 2.95 (very high zone) and 2.45 (high zone) $m$ above MLLW, 2 pairs of seeded and unseeded tiles were separated by a horizontal distance of $1 \mathrm{~m}$. Survival and recruitment were assessed on seeded and unseeded tiles, respectively. One randomly chosen pair was a Fucus canopy treatment and the other pair had no Fucus canopy. If a Fucus canopy was present in the no Fucus canopy treatment, the plants covering the tiles were removed. If there was no canopy in the Fucus canopy treatment, then Fucus plants collected

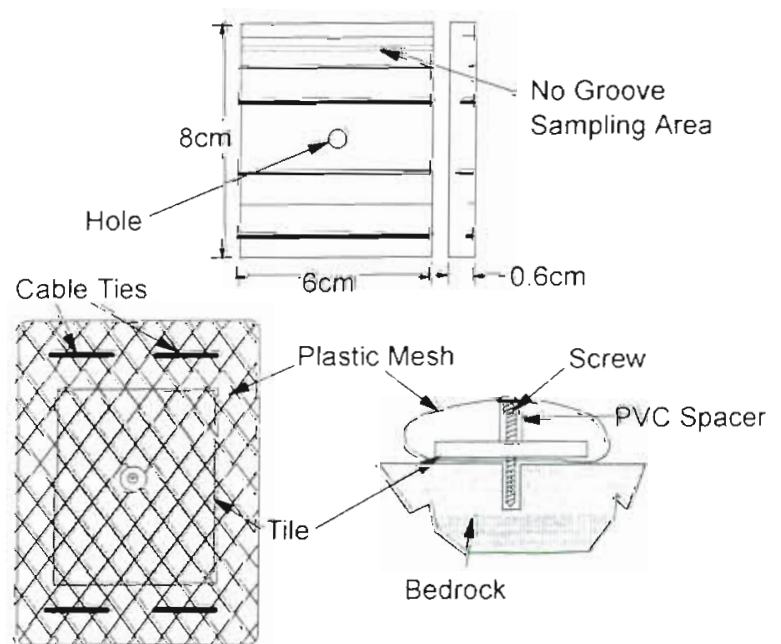

Fig. 3. Schematic diagram of a ceramic Fucus gardneri recruitment tile and a Vexar cage used to manipulate herbivores in this study. To control for cage effects, the cable ties were left of of one end of the Vexar cage such that the end of the cage was open to herbivores. Each tile had 6 grooves of 3 widths $(0.80,0.50$, and $0.15 \mathrm{~mm})$ and 2 depths $(1.50,0.30 \mathrm{~mm})$ 
from the same tidal height were transplanted just above the tiles. Fucus plants were collected for transplant by chipping off the rock with the plant attached and were transplanted using marine epoxy putty to secure the rock and plant in place. Each set of 8 tiles was randomly located on the shoreline at each site. The temperature of each tile was recorded on one hot. sunny day in July 1992 by inserting a thermocouple into a small hole on the side of each tile.

The effect of herbivores on germling survival was investigated using another set of seeded tiles. Herbivores were excluded by encasing tiles in Vexar mesh (about $3.5 \mathrm{~mm}$ mesh size) and securing the tile and cage to the substratum with a screw (Fig. 3). Control cages were open at one end, allowing herbivores access. Uncaged control tiles were also used. All tiles were seeded, and all Fucus canopy was removed from around the tiles. At each of the 6 sites, the 3 treatments were deployed at both $2.45 \mathrm{~m}$ (high) and $1.45 \mathrm{~m}$ (mid) above MLLW. The high set used the seeded tile with no Fucus canopy from the preceding experiment as the control tile. The 2 caging treatments were placed next to this control tile. The low treatments were placed directly (vertically) below the high caging treatments.

For all tiles, the number of germlings in each groove was counted using a dissecting microscope immediately before placement in the field. An area between the first and second grooves equal to the width of the widest groove was also counted to assess survival outside of grooves. In early September 1992, after 2 mo, and in June 1993, after $1 \mathrm{yr}$, the tiles were retrieved and the numbers of germlings were again counted using a dissecting microscope. After counting, which took about $10 \mathrm{~h}$, the tiles were returned to the field. In July 1993, May 1994, and September 1994, the number of plants in each groove visible to the naked eye was counted while the tiles were in the field. At the same time the lengths of the 5 largest plants in each groove were recorded.

For the experiments in the recruitment studies, ANOVAs were used on the raw data if variances were found to be homogeneous according to an F-max test. In cases where variances were not homogeneous, log transformations were used. In cases where variances remained non-homogeneous the ANOVA was carried out on the raw or transformed data, whichever had the most homogeneous variances.

\section{RESULTS}

\section{Fucus egg settlement}

There were always significantly more eggs settling at unoiled sites in the very high zone (Fig. 4). In the

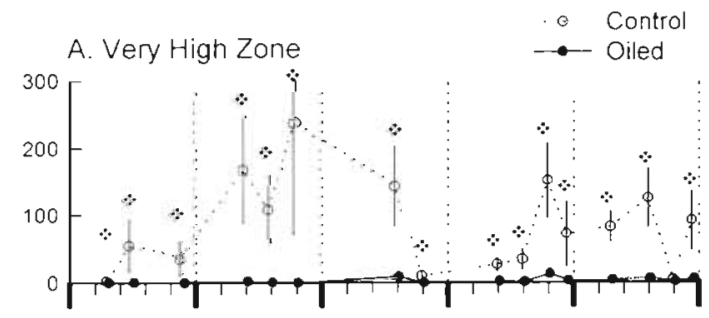

B. High Zone

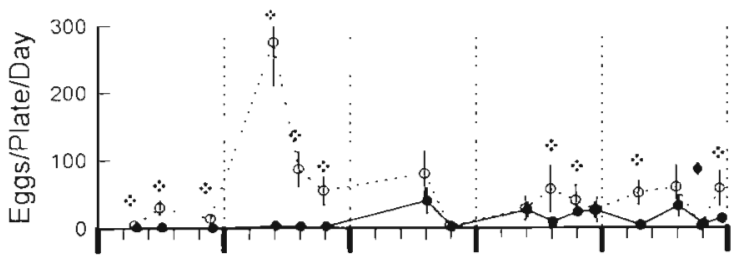

C. Mid Zone

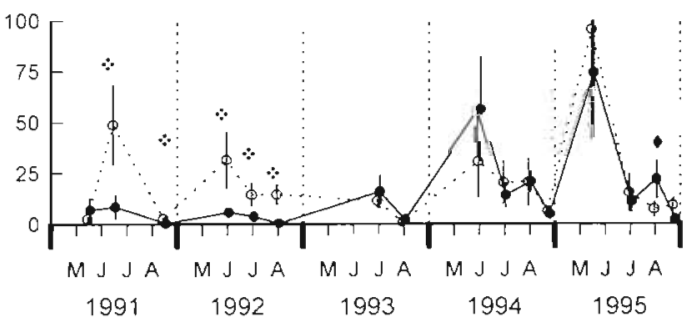

Fig. 4. Fucus gardnerı. Egg settlement at oiled and unoiled sites from May (M) to August (A) 1991 to 1995. The number of eggs caught per plate per day was averaged over all unoiled (O) and all oiled sites at the very high (2.95 $\mathrm{m}$ above MLLW), high (2.45 above MLLW), and mid (1.45 above MLLW) tidal levels. The sampling period was from May (M) 1991 to August (A) 1995. (*) Unoiled values were significantly $(p<0.05)$ greater than oiled values at that time. $(\bullet)$ Values for oiled sites were greater than values for unoiled sites. Fisher's procedure for combining probabilities of tests between specific site pairs was used (Sokal \& Rohlf 1981). Error bars show 1 SEM. Note the difference in $y$-axis scale for the mid zone

high and mid zones, with 1 exception, there were significantly more eggs at unoiled sites in 1991 and 1992. In the upper 2 tidal levels virtually no eggs settled at oiled sites in 1991 and 1992 while unoiled sites had average settlement rates of up to about 250 eggs per plate per day. By 1993 in the mid zone, settlement rates at oiled sites had increased to converge with those observed at unoiled sites, indicating some recovery from the effects of the oil spill. Convergence can also be seen in the high zone from 1993 onward, where settlement rates at oiled sites increased from 1991-92 levels to converge with unoiled levels, but occasionally ( 4 of 10 dates) there were still more eggs found at unoiled sites. In August 1995 there were more eggs at oiled sites in both the high and mid zones. Egg settlement rates at oiled sites in the very high zone increased slightly after 1992 but had not yet converged with unoiled site rates by 1995 

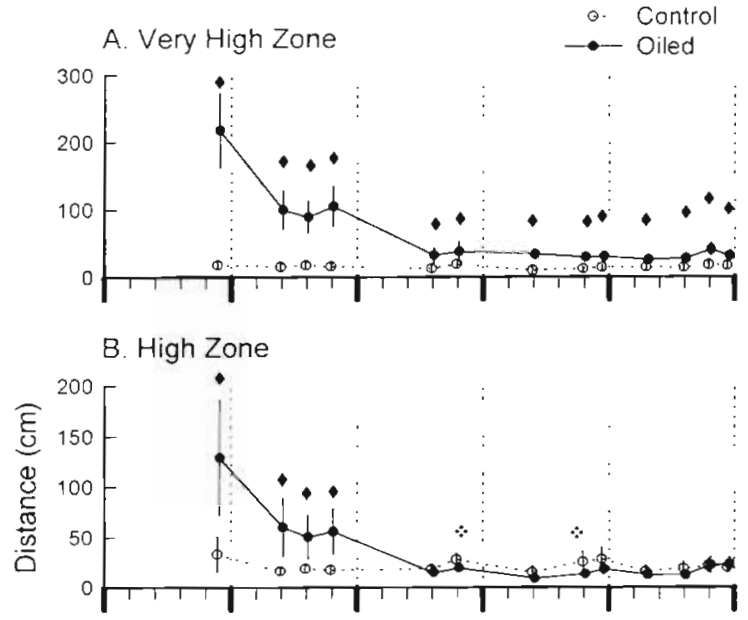

C. Mid Zone

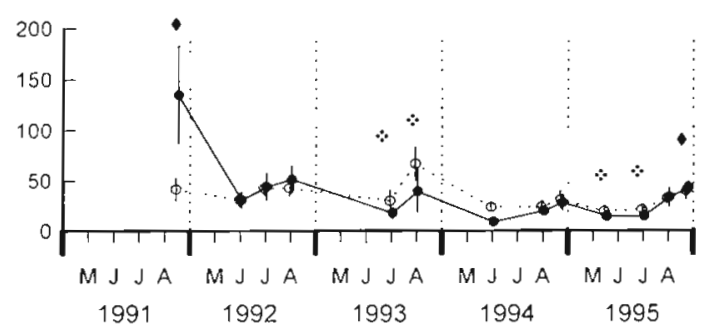

Fig. 5. Fucus gardneri. Distance to the nearest fertile Fucus plant from the egg settlement plates. Values were averaged over all unoiled and oiled sites at 3 tidal levels. Symbols as in Fig. 4

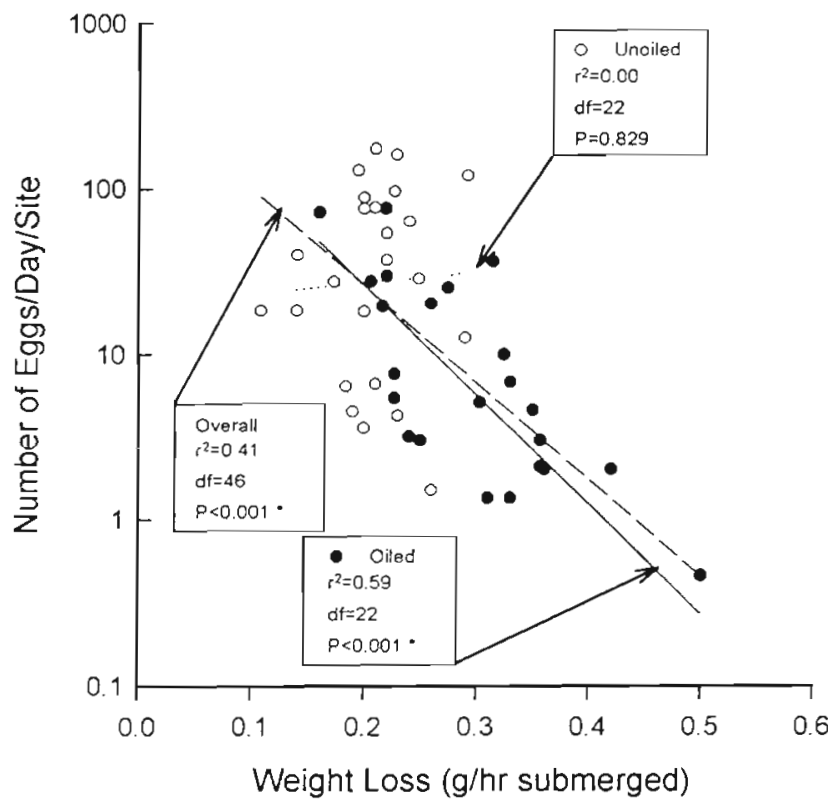

Fig. 6. Fucus gardneri. Egg settlement rate as a function of net water tlow expressed as loss in weight of plaster of Paris cylinders. Regressions for oiled and unoiled sites and for both are shown
In general, the distance to the nearest fertile Fucus plant, which is inversely related to the density of reproductive plants, was greater at oiled sites (Fig. 5). In the very high zone, the distance to the nearest fertile Fucus plant was significantly greater at oiled sites on all dates, but values began to converge in 1993. At all levels, the distance to the nearest fertile plant remained relatively constant at unoiled sites, but at oiled sites the distance decreased over time to converge with values for unoiled sites.

Water flow was inversely correlated with egg settlement rate when both oiled and unoiled sites or just oiled sites were considered (Fig. 6). Unoiled sites, however, showed no relationship between egg settlement and net flow.

\section{Fucus recruitment: desiccation and whiplash}

The percent cover of seeded germlings in dishes was negatively correlated with drying rate with an apparent threshold effect (Fig. 7). In areas where the desiccation rate exceeded about $0.2 \mathrm{~g} \mathrm{~h}^{-1}$, few germlings survived, while in areas with desiccation rates of less than about $0.15 \mathrm{~g} \mathrm{~h}^{-1}$ most of the germlings survived. Wetted cotton balls lost 10 to $20 \%$ of their total mass during the $5 \mathrm{~h}$ of the field desiccation trial.

Germlings growing on dishes subjected to whiplash from large plants showed high mortality. On control dishes, germling density remained at the original level

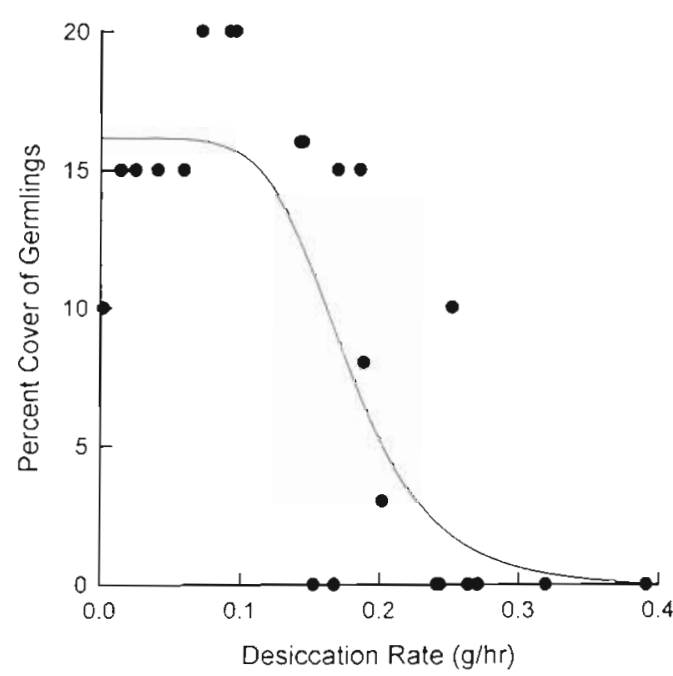

Fig. 7. Fucus gardneri. Relationship between measured desiccation rate and estimated percent cover of Fucus on petri dishes after being in the field for $11 \mathrm{~d}$. There is a significant linear regression $\left(r^{2}=0.524, d f=22, F=24.178, p<0.001\right)$, but the regression line is not shown. The sigmoid curve shown was generated by SigmaPlot (Version 5.0) using the curve fitting function 
Table 1. Fucus gardneri. Results of ANOVAs comparing the number and survival of Fucus germlings in different groove widths and depths. The tests were blocked by tiles, and in all cases blocking explained significant amounts of variation, reducing the effects of between-tile variation due to differences in germling density. Degrees of freedom (df) and p-values ( $p$ ) are given for each variable tested. The F/MSE column contains F-ratios $(F)$ for all tested terms and the mean square error term (MSE) in the last row of the column. The information provided is sufficient to reconstruct a regular ANOVA table. Data are shown in Fig. 9

\begin{tabular}{|c|c|c|c|c|c|c|c|c|c|}
\hline \multirow[t]{2}{*}{ Source } & \multicolumn{3}{|c|}{ Initial number } & \multicolumn{3}{|c|}{1992 survival $^{\text {a }}$} & \multicolumn{3}{|c|}{1993 survival } \\
\hline & $\mathrm{df}$ & F/MSE & $\mathrm{p}$ & $\mathrm{df}$ & $F / M S E$ & $\mathrm{p}$ & df & F/MSE & $\mathrm{p}$ \\
\hline Tile & 23 & 2.264 & $<0.001$ & 23 & 16.620 & $<0.001$ & 23 & 9.328 & $<0.001$ \\
\hline Depth (D) & 1 & 0.175 & 0.676 & 1 & 1.854 & 0.176 & 1 & 6.030 & 0.016 \\
\hline Width (W) & 2 & 21.034 & $<0.001$ & 2 & 7.841 & 0.001 & 2 & 6.214 & 0.003 \\
\hline$D \times W$ & 2 & 2.013 & 0.138 & 2 & 4.047 & 0.020 & 2 & 0.318 & 0.728 \\
\hline Error & 115 & 0.430 & & 115 & 3.342 & & 115 & 4.385 & \\
\hline
\end{tabular}

of $77.5( \pm 7.9, \mathrm{SE})$ per field of view at $25 \times[(p<0.010$, $\mathrm{df}=5$ ); in contrast, the density of germlings on dishes subjected to whiplash was about 2 orders of magnitude lower at $0.73( \pm 0.32, \mathrm{SE})$ per field of view). Germlings on dishes subjected to whiplash were found only along the edges of the dishes where adult fronds could not reach (i.e. make physical contact), suggesting that physical contact with the adult plants was necessary to remove germlings.

\section{Fucus recruitment: substrate heterogeneity}

The distribution of cracks in the natural substrate in Herring Bay ranged from 0.1 to $4.5 \mathrm{~mm}$. The largest percentage of cracks were in the range from 0.1 to $1.0 \mathrm{~mm}$, which included the sizes of the grooves in the tiles (Fig. 8). After 1 summer almost none of the seeded germlings outside of grooves on tiles survived, and after 1 yr none survived (Table 1, Fig. 9). In contrast about $10 \%$ of the seeded germlings survived in grooves. After 2 mo, the germling survival rate was

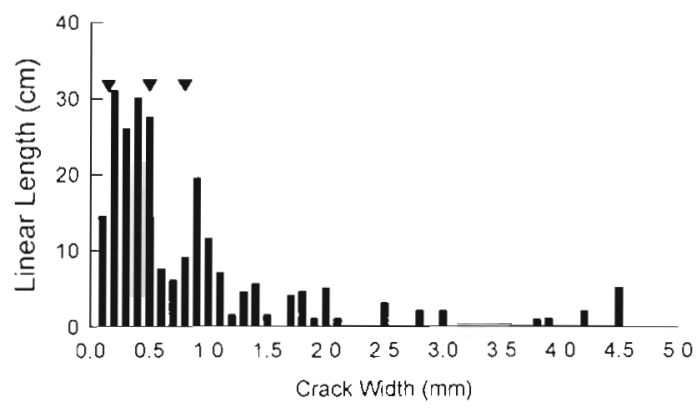

Fig. 8. Width frequency distribution of cracks in a $20 \times 50 \mathrm{~cm}$ plot on natural intertidal substrate in Herring Bay. The linear length of cracks is given for different crack widths, and the width of the grooves used on the ceramic tiles in this study are indicated by arrows higher in medium and narrow grooves than in wide grooves, especially in shallow grooves (Fig. 9, Table 1). After 1 yr, survival was greater in narrow relative to wide grooves, and in deep compared to shallow grooves (Fig. 9, Table 1).

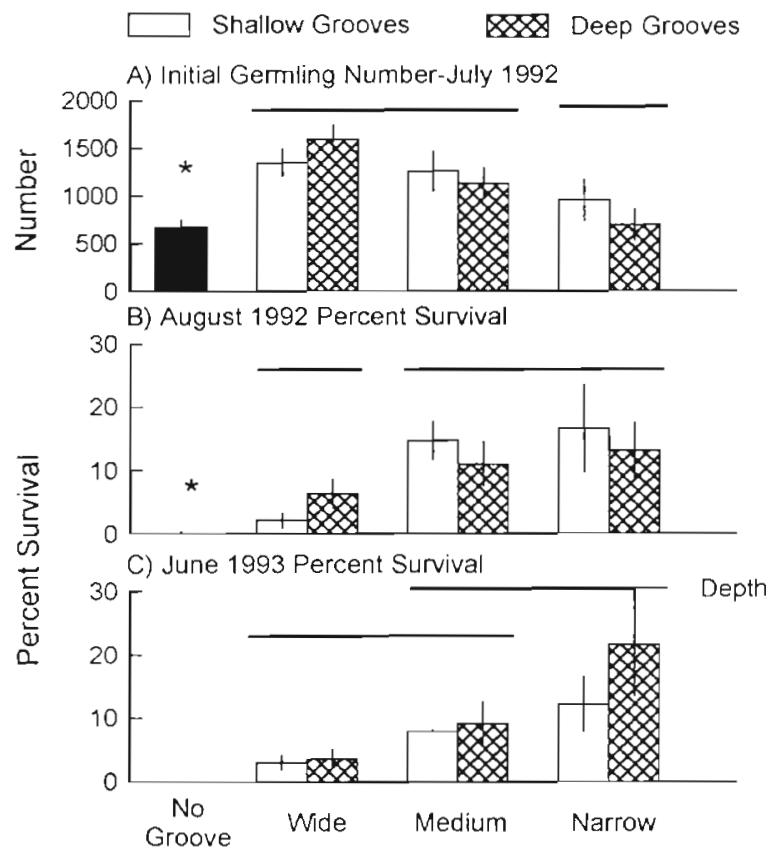

Fig. 9. Fucus gardneri. Initial Fucus seeding density and survival of seeded germlings in and outside of grooves of various sizes. To account for differences in initial seeding densities, percent survival of germlings was compared. Due to natural recruitment of germlings, it was possible for this value to be greater than 100 percent or to increase over time. Lines above graphs connect statistically indistinguishable groove widths. 'Depth' to the right of a graph indicates that there was a significant effect of depth, and an asterisk above the no groove treatment indicates a difference between grooves and no groove. Error bars show 1 SEM. Results of statistical analyses are given in Table 1 
Naturally recruiting germlings did not appear on the tiles outside of the grooves. No significant differences were detected among grooves in the number of microrecruits in August 1992 after $2 \mathrm{mo}$ in the field (Fig. 10A, Table 2). After 1 yr (June 1993) there were more microrecruits in medium and narrow grooves (Fig. 10B. Table 2) and in 1993 and 1994 there were more recruits in deep grooves (Fig. 10C, D, E, Table 2). After 2 yr the recruits fared better in medium grooves (Fig. 10D, E, Table 2)

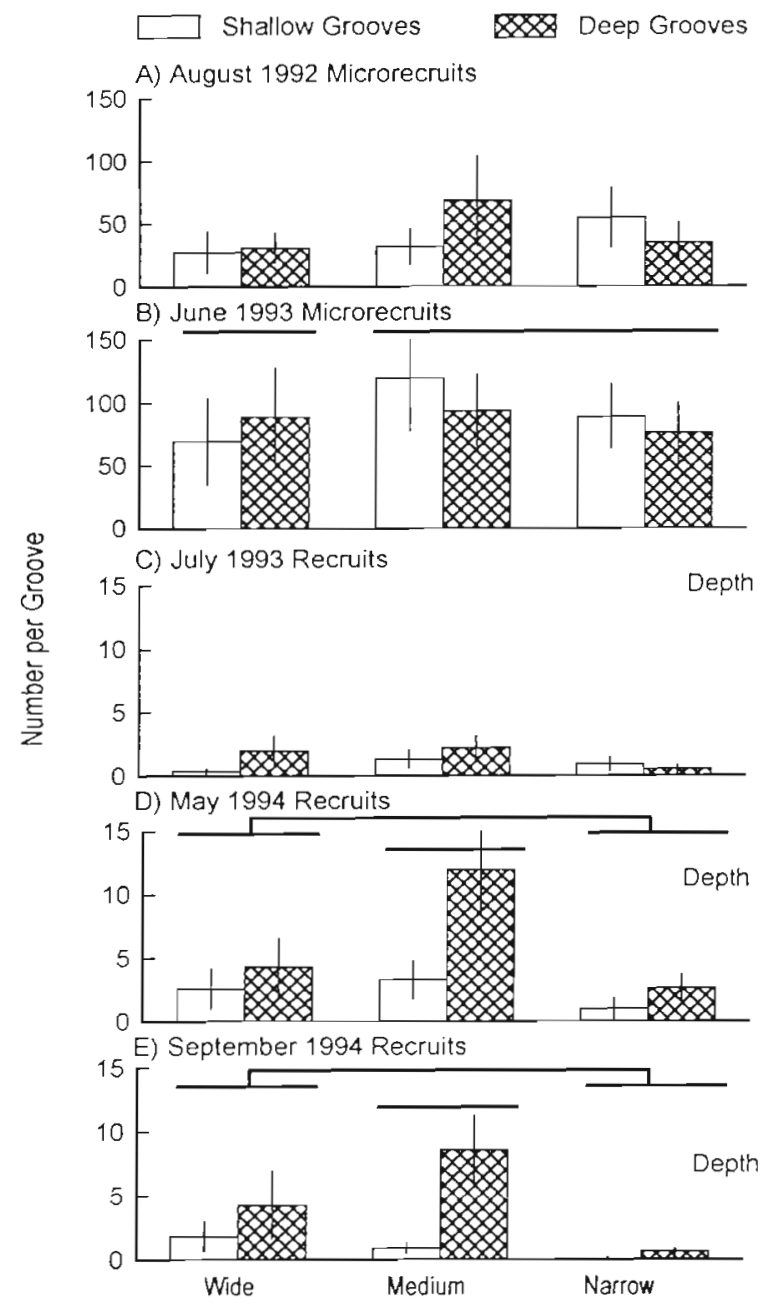

Fig. 10. Fucus gardnen. Recruitment of Fucus in grooves of vanous sizes. 'Microrecruits' were counted with a dissecting microscope and were only counted on unseeded tiles, while 'recruits' were counted with the unaided eye on both seeded and unseeded tiles. In July 1993 there was no difference in the number of visible germlings per tile: on seeded compared to unseeded tiles ( $t$-test, df $=45, \mathrm{p}=0.282$ ), so seeded and unseeded tiles were lumped for analyses after this date. 'Depth' to the right of a graph indicates that there was a significant effect of depth. Results of statistical analyses are given in Table 2

\section{Fucus recruitment: canopy, tidal height, and oiling}

Fucus microrecruits survived better and the number of recruits was greater under Fucus canopy and at unoiled sites (Fig. 11, Table 3) in August 1992 and July 1993. There were no other main treatment effects on any of the other dates sampled.

The temperature of the tiles on a hot day (July 1992) was significantly greater at oiled sites compared to unoiled sites, and tiles were significantly cooler under Fucus canopy than tiles with no canopy (Table 4 ). The maximum tile temperature recorded was $43.6^{\circ} \mathrm{C}$.

\section{Fucus recruitment: caging study}

The effect of cages and herbivores on germling recruitment was examined by evaluating the number of germlings per tile, ignoring groove size. The only significant effect of oiling, caging, or tidal zone on the survival of germlings was a tidal level $\times$ caging interaction in 1992 (Fig. 12, Table 5). In the high zone, but not the mid zone, there was higher survival in open and full cages than on uncaged tiles, suggesting an effect of the cages.

The number of subsequent recruits in 1993 showed significantly more recruits on fully caged tiles (Fig. 13A, Table 5), indicating an herbivore effect. By September 1994, the number of germlings on tiles with open cages had increased to equal the number on fully caged tiles, but the germling number on uncaged tiles remained significantly lower than that for either cage treatment. Thus, at the end of the experiment there was a significant cage effect. The length of germlings

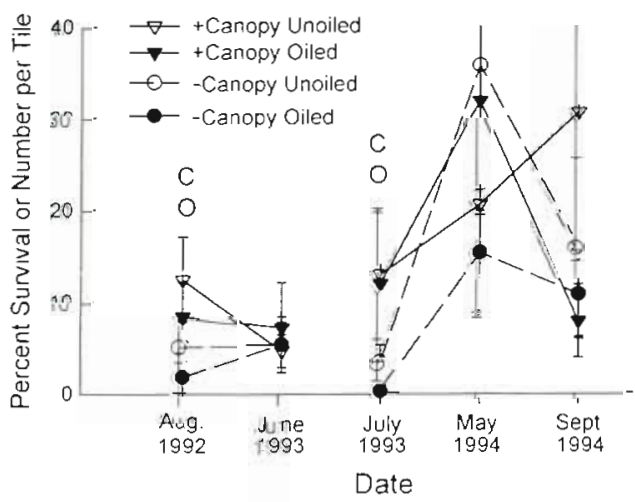

Fig. 11 Fucus gardneri. Percent survival of microrecruits or number of recruts on tiles at unoiled and oiled sites, with and without canopy. Percent survival is given for August 1992 and June 1993, and the number of visible recruits is given for the remaining 3 dates. Error bars show 1 SEM. Significant oiling (O) or canopy (C) effects from 3-way ANOVAs (Table 3 ) are indicated 
Table 2. Fucus gardneri. Results of ANOVAs comparing the number of microrecruits (counted with a dissecting microscope at $25 \times$ on unseeded tiles only) and recruits (counted with the unaided eye on both seeded and unseeded tiles) in different groove widths and depths. The tests were blocked by tiles, and in all cases blocking explained significant amounts of variation, reducing the effects of between tile varlation due to treatments imposed upon whole tiles. F/MSE as in Table 1 . Data shown in Fig. 10

\begin{tabular}{|c|c|c|c|c|c|c|c|c|c|c|c|c|c|c|c|}
\hline \multirow[t]{2}{*}{ Source } & \multicolumn{3}{|c|}{1992 microrecruits } & \multicolumn{3}{|c|}{1993 microrecruits $^{d}$} & \multicolumn{3}{|c|}{1993 recruits } & \multicolumn{3}{|c|}{ May 1994 recruits } & \multicolumn{3}{|c|}{ August 1994 recruits } \\
\hline & $\mathrm{df}$ & F/MSE & $\mathrm{p}$ & $\mathrm{df}$ & $F / M S E$ & $\mathrm{p}$ & $\mathrm{df}$ & F/MSE & $\mathrm{p}$ & df & F/MSE & $\mathrm{p}$ & $\mathrm{df}$ & F/MSE & $\mathrm{p}$ \\
\hline Tile & 23 & 11.724 & $<0.001$ & 23 & 14.090 & $<0.001$ & 46 & 3.780 & $<0.001$ & 46 & 3.701 & $<0.001$ & 46 & 2.127 & $<0.001$ \\
\hline Depth (D) & 1 & 0.148 & 0.701 & 1 & 1.662 & 0.200 & 1 & 5.280 & 0.022 & 1 & 8.968 & 0.003 & 1 & 15.630 & $<0.001$ \\
\hline Width (W) & 2 & 1.139 & 0.324 & 2 & 8.638 & $<0.001$ & 2 & 2.432 & 0.090 & 2 & 5.979 & 0.003 & 2 & 10.073 & $<0.001$ \\
\hline$D \times W$ & 2 & 0.110 & 0.896 & 2 & 0.472 & 0.625 & 2 & 1.069 & 0.342 & 2 & 0.410 & 0.664 & 2 & 1.636 & 0.197 \\
\hline Error & 115 & 6.027 & & 112 & 5.285 & & 230 & 3.171 & & 230 & 5.287 & & 230 & 5.017 & \\
\hline
\end{tabular}

"The test violated the assumption of homogeneity of variances

Table 3. Fucus gardneri. Results of ANOVAs companng the survival of seeded germlings and the number of recrults on tiles for the experiment testing canopy, oiling, and tidal level. The tests were blocked by the 3 pairs of sites where the experiment was conducted. F/MSE as in Table 1 Data shown in Fig. 11

\begin{tabular}{|c|c|c|c|c|c|c|c|c|c|c|c|c|c|c|c|}
\hline \multirow[t]{2}{*}{ Source } & \multicolumn{3}{|c|}{1992 survival } & \multicolumn{3}{|c|}{1993 survival } & \multicolumn{3}{|c|}{1993 recruits } & \multicolumn{3}{|c|}{ May 1994 recruits } & \multicolumn{3}{|c|}{ August 1994 recruits } \\
\hline & $\mathrm{df}$ & F/MSE & $p$ & df & F/MSE & $p$ & $d f$ & F/MSE & $\mathrm{p}$ & $\mathrm{df}$ & F/MSE & p & df & F/MSE & $\mathrm{p}$ \\
\hline Pair & 2 & 8.720 & 0.003 & 2 & 1.793 & 0.203 & 2 & 0.006 & 0.376 & 2 & 0.093 & 0.911 & 2 & 0.795 & 0.459 \\
\hline Oil $(\mathrm{O})$ & 1 & 7.404 & 0.017 & 1 & 0.151 & 0.704 & 1 & 5.423 & 0.025 & 1 & 0.513 & 0.478 & 1 & 0.423 & 0.520 \\
\hline Leve] (L) & 1 & 0.504 & 0.489 & 1 & 1.097 & 0.313 & 1 & 1.339 & 0.255 & 1 & 2.341 & 0.135 & 1 & 0.403 & 0.529 \\
\hline Canopy (C) & 1 & 10.509 & 0.006 & 1 & 0.029 & 0.867 & 1 & 8.736 & 0.005 & 1 & 0.076 & 0.784 & 1 & 0.127 & 0.723 \\
\hline $\mathrm{O} \times \mathrm{L}$ & 1 & 0.276 & 0.607 & 1 & 0.064 & 0.803 & 1 & 3.958 & 0.054 & 1 & 0.263 & 0.611 & 1 & 0.019 & 0.891 \\
\hline $\mathrm{O} \times \mathrm{C}$ & 1 & 0.129 & 0.725 & 1 & 0.156 & 0.699 & 1 & 0.010 & 0.921 & 1 & 0.953 & 0.335 & 1 & 0.069 & 0.794 \\
\hline $\mathrm{L} \times \mathrm{C}$ & 1 & 0.670 & 0.427 & 1 & 0.025 & 0.877 & 1 & 0.080 & 0.779 & 1 & 0.068 & 0.796 & 1 & 0.882 & 0.354 \\
\hline $\mathrm{O} \times \mathrm{L} \times \mathrm{C}$ & 1 & 0.553 & 0.469 & 1 & 1.560 & 0.232 & 1 & 2.524 & 0.121 & 1 & 6.205 & 0.017 & 1 & 3.193 & 0.082 \\
\hline Error & 14 & 4.598 & & 14 & 63.417 & & 37 & 8.451 & & 37 & 16.099 & & 37 & 14.382 & \\
\hline
\end{tabular}

was always greater on fully caged tiles compared to either open caged or uncaged tiles (Fig. 13B, Table 6).

\section{DISCUSSION}

Lower Fucus settlement rates at oiled sites compared to unoiled sites can be attributed to fewer reproductive plants at oiled sites. Other studies have also documented lower abundances of reproductive Fucus plants at sites impacted by this oil spill (Highsmith et al. 1996, Houghton et al. 1996, van Tamelen \& Stekoll 1996). Our general observation of low settlement rates

Table 4. Mean (SE) tile temperatures $\left({ }^{\circ} \mathrm{C}\right.$ ) at oiled and unoiled sites and with and without canopy. A 3-way ANOVA with oil, tidal level, and canopy yielded significant effects of both oil and canopy treatments; there was no effect of tidal height and no significant interactions

\begin{tabular}{|lcc|}
\hline & With canopy & Without canopy \\
\hline Unolled & $20.6(1.6)$ & $25.0(2.2)$ \\
Oiled & $23.3(1.6)$ & $28.4(2.5)$ \\
\hline
\end{tabular}

when the distance to the nearest reproductive plant was high can be explained by the fact that eggs rarely travel more than $50 \mathrm{~cm}$ from the parental plant and are

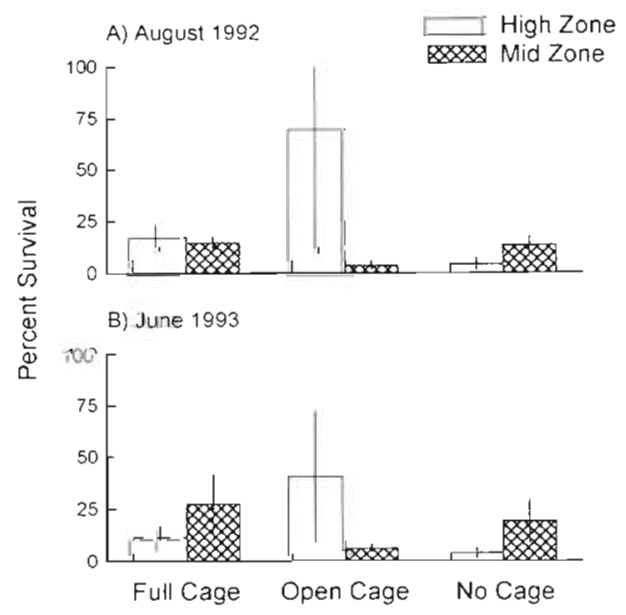

Fig. 12. Fucus gardneri. Percent survival of seeded Fucus germlings on tiles at 2 tidal levels for different caging treatments on 2 sampling dates. Error bars show 1 SEM. Results of statistical analyses are given in Table 5 
Table 5. Fucus gardneri. Results of ANOVAs comparing the survival of seeded germlings and the number of subsequent recruits on tiles for the experiment testing caging, oiling, and tidal level. The tests wrre blocked by the 3 pairs of sites where the experlment was conducted. F/MSE as in Table 1. Data shown in Figs. 12 \& $13 \mathrm{~A}$

\begin{tabular}{|c|c|c|c|c|c|c|c|c|c|c|c|c|c|c|c|}
\hline \multirow[t]{2}{*}{ Source } & \multicolumn{3}{|c|}{1992 survival } & \multicolumn{3}{|c|}{1993 survival } & \multicolumn{3}{|c|}{1993 recruits } & \multicolumn{3}{|c|}{ May 1994 recruits } & \multicolumn{3}{|c|}{ August 1994 recruits } \\
\hline & $\mathrm{df}$ & F/MSE & $p$ & $\mathrm{df}$ & $F / M S E$ & $\mathrm{p}$ & $\mathrm{df}$ & F/MSE & $\mathrm{p}$ & $\mathrm{df}$ & F/MSE & $\mathrm{p}$ & ds & F/MSE & $\mathrm{p}$ \\
\hline Pair & 2 & 1.773 & 0.193 & 2 & 8.797 & 0.002 & 2 & 0.518 & 0.603 & 2 & 1.572 & 0.230 & 2 & 1.600 & 0.225 \\
\hline Oil $(\mathrm{O})$ & 1 & 3.424 & 0.078 & 1 & 0.295 & 0.593 & 1 & 1.719 & 0.203 & 1. & 8.130 & 0.722 & 1 & 2.105 & 0.161 \\
\hline Level (L) & 1 & 1.048 & 0.317 & 1 & 1.675 & 0.209 & 1 & 0.001 & 0.970 & 1. & 0.043 & 0.837 & 1 & 1.279 & 0.270 \\
\hline Cage (C) & 2 & 3.061 & 0.067 & 2 & 3.309 & 0.055 & 2 & 5.791 & 0.010 & 2 & 2.397 & 0.114 & 2 & 4.121 & 0.030 \\
\hline$O \times L$ & 1 & 0.263 & 0.613 & 1 & 0.043 & 0.837 & 1 & 2.621 & 0.120 & 1 & 0.004 & 0.952 & 1 & 0.072 & 0.791 \\
\hline $\mathrm{O} \times \mathrm{C}$ & 2 & 0.443 & 0.648 & 2 & 0.246 & 0.784 & 2 & 0.225 & 0.800 & 2 & 0.069 & 0.934 & 2 & 1.041 & 0.370 \\
\hline $\mathrm{L} \times \mathrm{C}$ & 2 & 5.373 & 0.013 & 2 & 1.813 & 0.187 & 2 & 1.081 & 0.357 & 2 & 0.194 & 0.825 & 2 & 1.991 & 0.160 \\
\hline $\mathrm{O} \times \mathrm{L} \times \mathrm{C}$ & 2 & 0.234 & 0.793 & 2 & 0.101 & 0.904 & 2 & 0.579 & 0.569 & 2 & 0.376 & 0.691 & 2 & 3.745 & 0.040 \\
\hline Error & 22 & 3.517 & & 22 & 2.891 & & 22 & 1603.5 & & 22 & 2974.3 & & 22 & 2006.7 & \\
\hline
\end{tabular}

much more abundant near the source plant (McConnaughey 1985, van Tamelen \& Stekoll 1995). In the mid zone in 1992, however, the distance to the nearest reproductive plant converged between ailed and unoiled sites, but the settlement rate at oiled sites remained low. Van Tamelen \& Stekoll (1996) observed fewer receptacles per reproductive plant at oiled sites than at unoiled sites in Herring Bay, which may also contribute to lower settlement rates at oiled sites. These patterns of low settlement and reproductive plant density were spatially consistent, being observed at all 12 site pairs studied. Also, at the 2 pairs examined

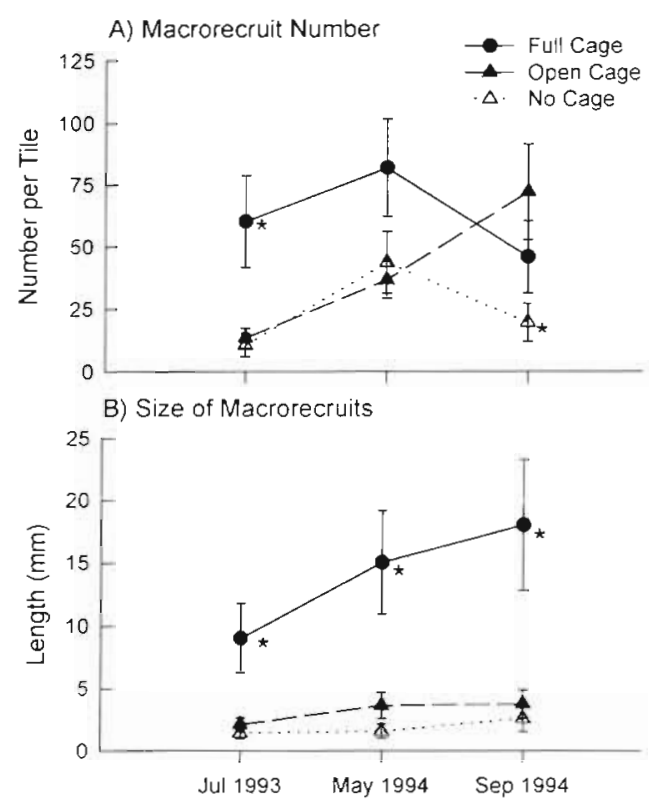

Fig. 13. Fucus gardneri. Number and size of recruits on tiles with different caging treatments. *Treatment was significantly different from the other 2 treatments $(p<0.05)$. Error bars show 1 SEM. Results of statistical analyses are given in Table 6 over the 5 yr of the study, the patterns were temporally consistent, showing recovery in lower zones and little or no recovery in the highest zones.

Since the oiled and unoiled sites were spatially segregated, it could be argued that the observed differences between oiled and unoiled sites could just be an effect of location in the bay. Ideally, oiled and unoiled sites would have been selected so that they were interspersed throughout the bay (Hurlburt 1984). Studies that rigorously sampled throughout Prince William Sound (Highsmith et al. 1996, Houghton et al. 1996) have shown essentially the same types and magnitudes of oil spill damage as a study in Herring Bay that compared the 2 sides of the bay (van Tamelen \& Stekoll 1996). If the southeastern (unoiled) portion of the bay had inherently higher egg settlement rates, then no convergence in settlement rates should be observed. Not only did we observe convergence, suggestive of recovery from the oil spill, we have also identified plausible mechanisms for the lower settlement rates at oiled sites. The combination of low dispersal distances and few reproductive plants have contributed to the low settlement rates at oiled sites.

Since oil is transported by currents, areas affected by oil spills may have higher water flows, which can influence settlement of Fucus spp. propagules. Vadas et al. $(1990,1992)$ found that Ascophyllum nodosum, and to a lesser extent Fucus evanescens, zygotes were susceptible to dislodgement by waves or constant flow. Norton \& Fetter (1981) compared the settlement of Sargassum muticum in stationary and flowing water and found that settlement was greater without moving water. Similar results were recently reported for other fucoids (Serrao et al. 1996). The results reported here document a negative correlation between fucoid settlement and water flow in the field, at least at oiled sites (Fig. 6). This correlation could be due to the fact that high water flow inhibits settlement (Norton \& Fetter 1981), inhibits release of propagules (Serrao et al. 
1996), or advects propagules immediately after settlement. Shores impacted by oil may have low settlement rates due to the currents that brought the oil initially.

After settlement of zygotes, cracks and crevices in the rock surface may enhance Fucus recruitment by providing protection from herbivores (Lubchenco 1983), desiccation, and whiplash. Up until now, there was no information regarding the optimal depth or width of cracks for fucoid recruitment. Similar to other studies of fucoids in other regions (Hawkins 1981, Lubchenco 1983, Farrell 1991), this study found that germlings survived poorly outside of grooves (Fig. 9B) and never recruited naturally outside of grooves (Fig. 10). Since the recruits visible after 1 yr were evenly dispersed among the groove widths, settlement appears to be unbiased toward groove width. After an initial even settlement, the chance of survival was greatest in grooves up to $500 \mu \mathrm{m}$ or about 6 times the diameter of a Fucus egg, and recruitment was greatest in deeper $(1500 \mu \mathrm{m})$ grooves. Wider grooves $(800 \mu \mathrm{m})$ may allow grazing by small littorinid snails and limpets while narrower $(150 \mu \mathrm{m})$ grooves may not allow germlings to grow larger since zygotes were only slightly smaller than the grooves. There may also be competition for wide grooves since barnacles recruited most abundantly to these grooves, often forming a line of new recruits only in the wide grooves (data not shown). Recovery rates of shores impacted by oil spills or other similarly large disturbances may be estimated from the size and abundance of cracks on the shore and the optimal size of cracks for recruitment.

Although cracks and crevices increased survival and recruitment, Fucus canopy also had positive effects on recruitment in Herring Bay (Fig. 11). The lack of significant canopy effects in 1994 may have been due to the loss of canopy plants over and near some tiles that were supposed to be in a canopy, but there may also have been negative effects of canopy on germlings Various studies have found that germlings may be brushed off the rock surface by adult plants as they are thrust back and forth by wave action (Dayton 1971, Menge 1976, Lubchenco 1986, Vadas et al. 1992, this paper). Conversely, at oiled sites lacking a healthy canopy of adult Fucus, germlings are subjected to increased heat and desiccation stress (Brawley \& Johnson 1991, 1993). In Herring Bay, it appears that the positive effects of Fucus canopy of reducing heat and desiccation stress outweigh the negative effects of whiplash by the canopy. Germling survival was found to be higher where desiccation stress was lower (Fig. 7), as well as under the Fucus canopy (Fig. 11). Germling survival was also lower at oiled sites lacking Fucus canopy and thus subjected to more severe heat and desiccation stress. Tile temperatures were lower under Fucus canopy and higher at oiled sites, with a maximum of $43.6^{\circ} \mathrm{C}$, showing that temperatures can be severe in this region. Although germlings recruiting under Fucus canopy may face survival challenges in the form of herbivory and whiplash, the alternative of recruiting in areas without Fucus canopy presents more severe threats to future survival by heating and desiccation stresses in higher intertidal zones.

The results of the caging study were not always easy to interpret, but the results were informative nonetheless. A cage effect was seen only in the high zone, and germling survival was less where desiccation was high (Fig. 7). The cage effect can be attributed to the reduction of heat and desiccation stress by the cages. This result is not surprising given our other results, indicating that desiccation is important in Herring Bay. The number of recruits was greater in full cages in 1993 , indicating that herbivores had a negative effect on recruitment (Fig. 13). In September 1994, however, the number of germlings on tiles in open cages had increased to equal the number on tiles in full cages, indicating that there was an effect of the cage itself. Thus, both the absence of herbivores and shading by cages promotes recruitment with the former acting

Table 6. Fucus gardneri. Results of ANOVAs comparing the sizes of germlings on tiles for the experiment testing caging, oiling, and tidal level. The tests were blocked by the 3 pairs of sites where the experiment was conducted. F/MSE as in Table 1. Tidal level was omitted as a factor in July 1993 since most tiles in the high zone were lacking germlings. Data shown in Fig. 13B

\begin{tabular}{|c|c|c|c|c|c|c|c|c|c|}
\hline \multirow[t]{2}{*}{ Source } & \multicolumn{3}{|c|}{ July 1993} & \multicolumn{3}{|c|}{ May 1994} & \multicolumn{3}{|c|}{ August 1994} \\
\hline & df & $F / \mathrm{MSE}$ & $\mathrm{p}$ & $\mathrm{df}$ & $F / \mathrm{MSE}$ & $\mathrm{p}$ & $\mathrm{df}$ & $F / \mathrm{MSE}$ & $\mathrm{p}$ \\
\hline Pair & 2 & 0.630 & 0.542 & 2 & 0.234 & 0.794 & 2 & 0.788 & 0.469 \\
\hline Oil (O) & 1 & 0.296 & 0.592 & 1 & 0.007 & 0.933 & 1 & 0.008 & 0.930 \\
\hline Level (L) & - & - & - & 1 & 0.653 & 0.429 & 1 & 0.986 & 0.333 \\
\hline Cage (C) & 2 & 3.864 & 0.037 & 2 & 6.434 & 0.008 & 2 & 7.388 & 0.004 \\
\hline $\mathrm{O} \times \mathrm{L}$ & - & - & - & 1 & 1.748 & 0.203 & 1 & 2.496 & 0.131 \\
\hline $\mathrm{O} \times \mathrm{C}$ & 2 & 0.239 & 0.789 & 2 & 0.029 & 0.971 & 2 & 0.046 & 0.955 \\
\hline $\mathrm{L} \times \mathrm{C}$ & - & - & - & 2 & 1.669 & 0.216 & 2 & 3.165 & 0.065 \\
\hline $\mathrm{O} \times \mathrm{L} \times \mathrm{C}$ & - & - & - & 2 & 1.120 & 0.348 & 2 & 1.458 & 0.258 \\
\hline Error & 21 & 44.490 & & 18 & 87.223 & & 18 & 112.33 & \\
\hline
\end{tabular}


faster than the latter. Herbivores affected germling size; germlings on tiles with full cages were 7 to 8 times longer than germlings on other tiles. This result could be a result of enhanced growth rate or an effect of cropping by herbivores on the uncaged tiles.

Fucus recolonization on impacted shores was probably controlled by the indirect effects of the oil spill and physical characteristics of sites rather than by any lingering effects of the oil. Settlement of Fucus eggs was greatly reduced, impeding recolonization where Fucus had been removed or damaged on a large scale by the oil spill and cleanup. Once eggs settled on a denuded shoreline, they faced additional barriers to recolonization. At denuded sites, since there was no protective Fucus canopy, germlings faced much greater desiccation and heat stress, leading to lower growth and survival rates. Lower germling growth rates increased the time spent in a stage more vulnerable to herbivory, whiplash, heat, and desiccation. further decreasing the chance of survival to adulthood. Cracks and crevices of appropriate size may ameliorate these sources of mortality, decreasing recovery times. Denuded sites tended also to have fewer herbivores (Highsmith et al. 1996), a factor that would enhance germling survival, recruitment, and growth at severely cleaned sites.

One method by which. recovery may proceed in areas which have lost all Fucus plants in the high intertidal is by expansion of Fucus beds from low in the intertidal and recruitment into cracks and crevices (Stekoll \& Deysher 1996). As Fucus plants lower in the intertidal or in cracks grow to reproductive status, they will provide both a source of eggs and protection from harsh conditions for germlings. Desiccation will be reduced in areas immediately surrounding the Fucus canopy where adult plants cover the rock surface during low tides. The boundaries of Fucus beds can slowly expand as plants on the edges grow, become reproductive, release eggs, and provide shelter for newly settled germlings.

Acknowledgements. A. Bernhard, C. Carlson, J. Jasper, M. Lindeberg, and B. Neilsen provided assistance in the field. The Jessen family, D. Doudna, H. Tominqas, and M. Gaeqle provided logistical support. WEST, Inc. helped with statistical analyses. C. Peterson, D. Boesch, and anonymous reviewers provided comments on earlier versions of this work. Financial support was provided by the U.S. Forest Service, Alaska Department of Fish and Game, and the 'Exxon Valdez' oil spill Trustee Council. The findings and conclusions presented by the authors, however, are their own and do not necessarily reflect the views or positions of the Trustee Council.

\section{LITERATURE CITED}

Barker KM, Chapman ARO (1990) Feeding preferences of periwinkles among tour species of Fucus. Mar Biol 106: $113-118$
Benecletti-Cecchi L, Cmelli F: (1992) Effects of canopy cover, herbivores and substratum type on patterns of Cystoseira spp. settlement and recruitment in littoral rockpools. Mar Ecol Prog Ser 90:183-191

Brawley SH, Johnson LE (1991) Survival of fucoid embryos in the intertidal zone depends upon developmental stage and microhabitat. J Phycol 27:179-186

Brawley SH, Johnson LE (1993) Predicting desiccation stress in microscopic organisms: the use of agarose beads to determine evaporation within and between intertidal microhabitats. J Phycol 29:528-535

Chapman ARO (1989) Abundance of Fucus spiralis and ephemeral seaweeds in a high eulittoral zone: elfects of grazers, canopy and substratum type. Mar Biol 102: $565-572$

Chapman ARO (1995) Functional ecology of fucoid algae: twenty-three years of progress. Phycologia 34:1-32

Chapman ARO, Johnson CR (1990) Disturbance and organization of macroalgal assemblages in the Northwest Atlantic. Hydrobiologia 192:77-121

Connell JH (1985) The consequences of variation in initial settlement vs post settlement mortality in rocky high intertidal communities. J Exp Mar Biol Ecol 93:11-45

Dayton PK (1971) Competition, disturbance and community organization: the provision and subsequent utilization of space in a rocky intertidal community. Ecol Monogr 41: 351-389

Denley EJ, Underwood AJ (1979) Experiments on factors influencing settlement, survival, and growth of two species of barnacles in New South Wales. J Exp Mar Biol Ecol 36:269-293

Dethier MN, Graham ES, Cohen S, Tear LM (1993) Visual versus random-point percent cover estimations: 'objective is not always better. Mar Ecol Prog Ser 96:93-100

De Vogelaere AP, Foster MS (1994) Damage and recovery in intertidal Fucus gardneri assemblages following the 'Exxon Valdez' oil spill. Mar Ecol Prog Ser 106:263-271

Farrell TM (1991) Models and mechanisms of succession: an example from a rocky intertidal community. Ecol Monogr $61: 95-113$

Hartnoll RG, Hawkins SJ (1985) Patchiness and fluctuations on moderately exposed rocky shores. Ophelia 24:53-63

Hawkins SJ (1981) The influence of season and barnacles on the algal colonization of Patella vulgata exclusion areas. J Mar Biol Assoc UK 61:1-15

Highsmith R, Rucker TL, Stekoll MS, Saupe SM, Lindeberg MR, Jenne RN, Erickson WP (1996) Impact of the Exxon Valdez oil spill on intertidal biota. In: Rice SD, Spies RB, Wolfe DA, Wright BA (eds) Exxon Valdez oil spill symposium proceedings. Am Fish Soc Symp 18:212-237

Houghton JP, Lees DC, Driskell WB, Lindstrom SC, Mearns A.J (1996) Recovery of Prince William Sound intertidal epibiota from Exxon Valdez oiling and shoreline treatments, 1989 through 1992. In: Rice SD, Spies RB, Wolfe DA, Wnght BA (eds) Exxon Valdez oil spill symposium proceedings. Am Fish Soc Symp 18:379-411

Hurlbert SH (1984) Pseudoreplication and the design of ecological field experiments. Ecol Monogr 54:187-211.

Jernakoff P (1983) Factors affecting the recruitment of algae in a midshore region dominated by barnacles. J Exp Mar Biol Ecol 67:17-31

Jernakoff P (1985) An experimental evaluation of the influence of barnacles, crevices and seasonal patterns of grazing on algal diversity and cover in an intertidal barnacle zone. J Exp Mar Biol Ecol 88:287-302

Kendrick GA, Walker DI (1991) Dispersal distance for propagules of Sargassum spinuligerum (Sargassaceae: Phaeo- 
phyta) measured directly by vital staining and venturi suction sampling. Mar F col Prog Ser 79:133-138

Lees D, Houghton JP, Driskell WB (1996) Short-term effects of several types of shoreline treatment on rocky intertidal biota in Prince William Sound. In: Rice SD, Spies RB, Wolfe DA, Wright BA (eds) Exxon Valdez oil spill symposium proceedings. Am Fish Soc Symp 18:32.9-348

Lubchenco J (1983) Littorina and Fucus; effects of herbivores, substratum heterogeneity, and plant escapes during succession. Ecology 64:1116-1123

Lubchenco J (1986) Relative importance of competition and predation: early colonization by seaweeds in New England. In: Diamond J, Case TJ (eds) Community ecology. Harper \& Row, New York, p 537-555

McConnaughey J (1985) The growth and regeneration of the rockweed, Fucus distichus, in Bristol Bay. MSc thesis, University of Alaska, Juneau

Mearns AJ (1996) Exxon Valdez shoreline treatment and operations: implications for response, assessment, monitoring, and research. In: Rice SD, Spies RB, Wolfe DA, Wright BA (eds) Exxon Valdez oil spill symposium proceedings. Am Fish Soc Symp 18:309-328

Menge BA (1976) Organization of the New England rocky intertidal community: the role of predation, competition and envronmental heterogeneity. Ecol Monogr 46: 355-393

Menge BA (1991) Relative importance of recruitment and other causes of variation in rocky intertidal community structure. J Exp Mar Biol Ecol 146:69-100

Nauman SA (1991) Shoreline cleanup: equipment and operations. In: Proc 1991 international oil spill conference. Publication 4529, American Petroleum Institute, Washington, DC, p 141-147

Norton TA (1983) The resistance to dislodgement of Sargassum muticum germlings under defined hydrodynamic conditions. J Mar Biol Assoc UK 63:181-193

Norton TA, Fetter R (1981) The settlement of Sargassum muticum propagules in stationary and flowing water. J Mar Biol Assoc UK 61:929-940

Paine RT, Ruesink JL, Sun A, Soulanille EL, Wonham MJ, Harley CDG, Brumbaugh DR, Secord DL (1996) Trouble on oiled waters: lessons from the Exxon Valdez oil spill.

Editorial responsibility: Charles Peterson /Contributing

Editor), Morehead City, North Carolina, USA
Annu Rev Ecol Syst 27:197-235

Rolan GR, Gallagher R (1991) Recovery of the intertidal biotic communities at Sullum Voe following the Esso Bernicia oil spill of 1978. In: Proc 1991 international orl spill conference: prevention, behavior, control, cleanup. Publication 4529. Amoncan Petrolcum Institute, Washington, DC, $p$ $461-465$

Roughgarden J, Gaines S, Possingham H (1988) Recruitment dynamics in complex lifecycles. Science 241:1460-1466

Santelices B (1990) Patterns of reproduction, dispersal and recruitment in seaweeds. Oceanogr Mar Biol Annu Rev 28:177-276

Serrao EA, Pearson G, Kautsky L, Brawley SH (1996) Successfuil external fertilization in turbulent environments. Proc Natl Arad Sci 93:5286-5290

Sokal RR, Rohlf FJ (1981) Brometry. Why Freeman and Co, San Francisco, CA

Southward AJ, Southward EC (1978) Recolonization of rocky shores in Cornwall after use of toxic dispersants to clean up the Torrey Canyon spill. J Fish Res Bd Can 10:582-706

Stekoll MS, Deysher L (1996) Recolonization and restoration of upper intertidal Fucus gardneri (Fucales, Phaeophyta) following the Exxon Valdez oil spill. Hydrobiologia 326/ 327:311-316

Vadas RL, Johnson S, Norton TA (1992) Recruitment and mortality of early post-settlement stages of benthic algae. Br Phycol J 27:331-351

Vadas RL, Wright WA, Miller SL (1990) Recruitment of Ascophyllum nodosum: wave action as a source of mortality. Mar Ecol Prog Ser 61:263-272

van Tamelen PG. Stekoll MS (1995) Recovery mechanisms of the brown alga, Fucus gardneri, folluwing catastrophic disturbance: lessons from the Exxon Valdez oil spill. In: Engstrom DR (ed) Proc 3rd Glacier Bay Science Symp. US Department of the lnterior, National Park Service, Alaska Regional Office, Anchorage, p 221-228

van Tamelen PG, Stekoll MS (1996) Population response of the brown alga, Fucus gardneri, and other algae in Herring Bay, Prince William sound, to the Exxon Valdez oil spill. In: Rice SD, Spies RB, Wolfe DA, Wright BA (eds) Exxon Valdez oil spill symposium proceedings. Am Fish Soc Symp 18:193-211

Submitted: October 24, 1996; Accepted: September 19, 1997 Proofs received from author(s): December 1, 1997 